\title{
INTERPRETIVE SUMMARIES, APRIL 2013
}

Invited review: Sensors to support health management on dairy farms. By Rutten et al., page 1928. This review presents an overview of the sensor systems (that is, sensors plus software) that have been published for dairy health management. Dairy farmers can use sensor systems to improve animal health and welfare on dairy farms, which in turn helps increase profitability. The usefulness of such sensor systems depends on the level of development, which is described here through a framework that includes 4 levels: technique, interpretation of data, integration of information, and decision making. The sensor systems are compared based on this framework. The review provides information about the possibilities and limits of published sensor systems, as well as suggestions for future research.

http://dx.doi.org/10.3168/jds.2012-6107.

Physicochemical and sensory characterization of Cheddar cheese with variable $\mathrm{NaCl}$ levels and equal moisture content. By Møller et al., page 1953. The effect of varying the level of $\mathrm{NaCl}$ (salt) on the flavor and texture of Cheddar cheese manufactured with equal amounts of moisture was thoroughly mapped using instrumental and sensory methods. Moisture adjustment contributed to largely unaffected textural properties upon a 50\% salt reduction; however, the flavor deteriorated gradually with decreasing $\mathrm{NaCl}$ concentration. Above all, flavor restoration required careful engineering of the basic taste profile of the cheese. The present results aid the cheese industry in approaching significant salt reductions in Cheddar while preserving cheese flavor and texture, and thereby meet a global demand for lower sodium foods.

http://dx.doi.org/10.3168/jds.2012-5524.

Influence of fat replacement by inulin on rheological properties, kinetics of rennet milk coagulation, and syneresis of milk gels. By Arango et al., page 1984. Dairy products can provide major opportunities for the development of functional foods. We have evaluated the effect of replacing fat with inulin on the rheological properties, coagulation kinetics, and syneresis of milk gels. Inulin addition increased the rates of aggregation and curd firming reactions in the casein gels and produced a significant reduction in syneresis. Therefore, the use of inulin as a fat replacer on milk gels reduced cutting time and increased curd yield. These results may contribute to our understanding of the technological impact of the incorporation of inulin into milk products.

http://dx.doi.org/10.3168/jds.2012-5763.

Prevalence and antimicrobial susceptibility of Acinetobacter from raw bulk tank milk in Korea. By Gurung et al., page 199\%. An increasing number of people consume unpasteurized milk despite the hazards associated with this practice. Examination of bulk tank milk (BTM) is important not only for foodborne pathogens but also for other gram-negative bacteria including Acinetobacter spp., which could be a public health concern. A better understanding of resistance profiles of BTM isolates would help us better understand treatment options of diseases caused by them. This is the first report to provide a prevalence of Acinetobacter spp., including Acinetobacter baumannii, and their resistance profiles in BTM samples from different provinces of Korea.

http://dx.doi.org/10.3168/jds.2012-5965.

Gravity separation of fat, somatic cells, and bacteria in raw and pasteurized milks. $B y C a$ plan et al., page 2011. Gravity separation concentrates somatic cells and bacteria more effectively than milk fat near the top of a tank of raw milk left undisturbed at $4^{\circ} \mathrm{C}$ overnight. Pasteurization at $72.6^{\circ} \mathrm{C}$ for $25 \mathrm{~s}$ improved the effectiveness of gravity separation of the viable bacteria and somatic cells. Pasteurization at higher temperatures prevented gravity separation. Gravity separation of milk has been used in the manufacture of traditional Italian cheeses to adjust the level of fat in cheese milk, but may provide additional cheese quality and safety benefits beyond fat adjustment. http://dx.doi.org/10.3168/jds.2012-6006.

Serum protein removal from skim milk with a 3 -stage, $3 \times$ ceramic Isoflux membrane process at $50^{\circ} \mathrm{C}$. By Adams and Barbano, page 2020. Microfiltration can be used to remove serum proteins from skim milk. The removal efficiency of the process directly influences the technology's economic feasibility. Our objective was to quantify the capacity of $0.14-\mu \mathrm{m}$ ceramic Isoflux microfiltration membranes to remove serum proteins from skim milk. Contrary to theoretical cumulative serum protein removal percentages of 68 , 90 , and $97 \%$ after 1,2 , and 3 stages of $3 \times$ microfiltration processing, respectively, the $3 \times$ Isoflux process removed only $39.5,58.4$, and $70.2 \%$ after 1,2 , and 3 stages, respectively. This serum protein removal was lower than reported values for other commercially available ceramic membranes.

http://dx.doi.org/10.3168/jds.2012-6007.

Effect of annatto addition and bleaching treatments on ultrafiltration flux during production of $80 \%$ whey protein concentrate and $\mathbf{8 0 \%}$ serum protein concentrate. By Adams et al., page 2035. The goals of this study were to determine if adding annatto color to milk or bleaching whey or microfiltration permeate would influence ultrafiltration flux, diafiltration flux, or membrane fouling during 
production of $80 \%$ whey protein concentrate or $80 \%$ serum protein concentrate. Addition of annatto color to milk had no effect on flux or fouling. Bleaching with or without added color improved flux during processing. Bleaching with hydrogen peroxide produced greater flux than bleaching with benzoyl peroxide. Bleaching with hydrogen peroxide led to the largest reduction in fouling.

http://dx.doi.org/10.3168/jds2012-6009.

Influence of casein on flux and passage of serum proteins during microfiltration using polymeric spiral-wound membranes at $50^{\circ} \mathrm{C}$. By Zulewska and Barbano, page 2048. A study was carried out to determine the effect of fouling of polymeric microfiltration (MF) membranes on whey protein passage through the membrane. When processing skim milk with a spiralwound polymeric MF membrane, casein was the major protein foulant that increased hydraulic resistance and reduced whey protein passage through the membrane. Isolation of whey proteins directly from skim milk produces a value-added milk protein ingredient for protein fortification of foods.

http://dx.doi.org/10.3168/jds.2012-6032.

Stability during in vitro digestion of lactoferrinloaded liposomes prepared from milk fat globule membrane-derived phospholipids. By Liu et al., page 2061. Lactoferrin is considered to be an important protein for human health because it is able to bind ferric irons and has bacteriostatic, bactericidal, and fungistatic activities. In this study, we characterized the entrapment efficiency of lactoferrin in a liposome prepared from milk fat globule membrane-derived phospholipids and examined the stability of the lactoferrin loaded in the liposome during in vitro digestion in the gastrointestinal tract. Liposomes may prevent the gastric degradation of lactoferrin and may result in an increase in active lactoferrin for absorption in the intestine.

http://dx.doi.org/10.3168/jds.2012-6072.

Monitoring lactic acid production during milk fermentation by in situ quantitative proton nuclear magnetic resonance spectroscopy. By Bouteille et al., page 20\%1. During milk fermentation, microorganisms produce lactic acid, which causes the jellification of caseins, leading to dairy gels such as yogurts. The determination of lactic acid content is thus essential to control manufacturing processes and storage of dairy gels, in particular to evaluate bacteria efficiency. An easy-to-implement solvent-free experimental method was investigated to monitor lactic acid during fermentation: in situ quantitative nuclear magnetic resonance spectroscopy enabled quantification of lactic acid and lactose, allowing cross-validation.

http://dx.doi.org/10.3168/jds.2012-6092.
Starter cultures and cattle feed manipulation enhance conjugated linoleic acid concentrations in Cheddar cheese. By Mohan et al., page 2081. Conjugated linoleic acid (CLA) is a fatty acid associated with numerous health benefits, including an anticarcinogenic effect. The amount of CLA in the daily diet, however, remains low. We proposed to enhance the CLA content in Cheddar cheese produced with milk from cattle fed diets supplemented with fish oil and made with a CLA-producing starter culture. In cheeses ripened for $6 \mathrm{mo}$, the CLA content in cheese made using the CLA-producing culture and milk from cattle fed fish oil diets was 2.6 times that of cheese made using non-CLA-producing culture and milk from cattle fed unsupplemented diets.

http://dx.doi.org/10.3168/jds.2012-6101.

Influence of fresh forage-based diets and $\alpha_{\mathrm{S1}^{-}}$ casein (CSN1S1) genotype on nutrient intake and productive, metabolic, and hormonal responses in milking goats. By Bonanno et al., page 210\%. Polymorphism at the $\alpha_{\mathrm{S} 1}$-casein locus (CSN1S1) in goats influences several milk production traits that are also affected by nutrition. The aim of this study was to investigate how the interaction between diet characteristics and CSN1S1 genotype affected the feeding behavior, milk production, and metabolic and hormonal parameters of Girgentana goats. Diet had a stronger effect than CSN1S1 genotype. Goats with a greater capacity for $\alpha_{S 1}$-casein synthesis exhibited more efficient energy and protein utilization, which was evident at the digestive level, and had better productive responses to high-nutrition diets.

http://dx.doi.org/10.3168/jds.2012-6244.

Short communication: Rapid detection of milk fat adulteration with vegetable oil by fluorescence spectroscopy. By Ntakatsane et al., page 2130. Adulteration of high-value food products with cheap and readily available components is a serious concern for the food industry, and the lack of rapid detection techniques exacerbates the situation. In this study, we developed a rapid analytical technique based on frontface fluorescence spectroscopy (FFFS) for detection of milk fat adulteration with vegetable oil. The study demonstrated the ability and sensitivity of FFFS to rapidly discriminate between commercial and adulterated milk samples.

http://dx.doi.org/10.3168/jds.2012-6417.

Effects of bail activation sequence and feed availability on cow traffic and milk harvesting capacity in a robotic rotary dairy. By Kolbach et al., page 213\%. This manuscript reports the effects of different bail activation sequences and feed availability on cow traffic and system efficiency in the world's first high-throughput automatic milking system, the robotic 
rotary. Overall, the availability of feed as cows enter the platform had a greater effect on cow traffic than did the bail activation sequence. More consecutive bails activated (rather than intermittent) resulted in more robot operations being conducted simultaneously, resulting in an increased milk harvesting efficiency.

http://dx.doi.org/10.3168/jds.2012-5332.

An optimization model of a New Zealand dairy farm. By Doole et al., page 214\%. Dairy farms are complex systems in which many elements are interdependent. This study outlined a comprehensive mathematical model that describes many of the important elements and their relationships. The model incorporated many detailed processes not included in simpler, linear models of its kind. Accordingly, the model provided a meaningful description of experimental data from a farm system trial. In contrast, a less-detailed linear model was less able to describe the same data. The model may be used to predict how farmers may best respond to new constraints and opportunities, such as new environmental policies.

http://dx.doi.org/10.3168/jds.2012-5488.

Generation of an index for physiological imbalance and its use as a predictor of primary disease in dairy cows during early lactation. By Moyes et al., page 2161. Predicting physiological imbalance (PI), a situation in which physiological parameters deviate from normal, is needed to reduce disease risk and improve production and reproduction performance of cows. An index for PI was generated based on plasma nonesterified fatty acids (NEFA), bhydroxybutyrate (BHBA), and glucose. Prepartal PI index and plasma NEFA were better predictors of risk for disease after calving than calculated energy balance or plasma BHBA and glucose. Further investigations will be needed to generate a system for surveillance of PI on-farm to improve animal health and welfare and economic outcome to the farmer.

http://dx.doi.org/10.3168/jds.2012-5646.

Change in subcutaneous adipose tissue metabolism and gene network expression during the transition period in dairy cows, including differences due to sire genetic merit. By Khan et al., page 2171. Sire genetic merit and dietary energy intake affect adipose tissue metabolism in the transition period. These adaptions are controlled by different mechanisms and are dynamic over time. Lipogenesis rates and gene expression decreased after parturition, with the latter being more pronounced in high-geneticmerit cows. Lipolysis rates increased after parturition to a greater extent in high-genetic-merit cows, but changes in gene expression were minor. This confirms that anabolic reactions in adipose are controlled at the transcription level, whereas catabolic (fatty acid release) reactions are controlled primarily through posttranslational modification by endocrine or neurocrine signaling in early lactation. This knowledge could improve our models of metabolism in dairy cattle and enhance productive efficiency.

http://dx.doi.org/10.3168/jds.2012-5794.

Preferences of processing companies for attributes of Swiss milk: A conjoint analysis in a business-to-business market. By Boesch, page 2183. We conduct a standardized survey to ask Swiss producers of dairy products about their preferences for milk attributes such as price, origin, or technical qualities. The attributes used in the survey were collected through qualitative interviews at different stages of the value chain. Through simulations, we showed the influence of each attribute on the buying decision. Price and country of origin are important criteria, but environmental and societal attributes might also show potential for differentiation. Additionally, preferences differed according to final products sold. Market segmentation along product lines might thus be a future sales strategy for Swiss dairy farmers.

http://dx.doi.org/10.3168/jds.2012-5887.

Association between digital dermatitis lesions and test-day milk yield of Holstein cows from 41 French dairy farms. By Relun et al., page 2190. Digital dermatitis (DD) is one of the most frequent causes of lameness in dairy herds. Although farmers recognize that DD is problematic, the implementation of control measures may be limited by uncertainty concerning its effect on cow performance. This study investigated the effect of DD lesions on milk yield, taking into account their severity. Monthly test-day milk yields of 1,782 Holstein cows from 41 French dairy herds were analyzed. Active DD lesions had a slight but significant effect on milk yield regardless of the severity. This effect should be considered when estimating the cost-benefits of DD control programs.

http://dx.doi.org/10.3168/jds.2012-5934.

Feed restriction, but not L-carnitine infusion, alters the liver transcriptome with an evident induction of gluconeogenesis and inhibition of energy capture and sterol synthesis in midlactation dairy cows. By Akbar et al., page 2201. Microarrays allow large-scale examination of tissue gene expression changes that could play a mechanistic role during health and disease. Supplemental L-carnitine stimulates fatty acid oxidation and decreases liver lipid accumulation. We performed liver transcriptome analyses in mid-lactation cows that were feed-restricted and infused into the abomasum with L-carnitine or water. Bioinformatics analysis uncovered that feed restriction, and not L-carnitine, had a marked effect on hepatic gene expression profiles, indicating an induction of in- 
flammation and oxidative stress with an inhibition of cholesterol biosynthesis. These findings may be useful in developing strategies to alleviate the risk of lipidosis in dairy cattle.

http://dx.doi.org/10.3168/jds.2012-6036.

Targeted progesterone supplementation improves fertility in lactating dairy cows without a corpus luteum at the initiation of the timed AI protocol. By Bisinotto et al., page 2214. Dairy cows that lack a corpus luteum (CL) at the initiation of the timed artificial insemination (AI) program have reduced fertility because of inadequate concentrations of progesterone during follicle growth. A single ultrasound examination concurrently with the first gonadotropinreleasing hormone $(\mathrm{GnRH})$ of the 5-d timed AI protocol was effective in identifying a low-fertility cohort of cows based on the absence of a CL. The use of 2 intravaginal progesterone inserts increased circulating progesterone in lactating dairy cows without a CL. Progesterone supplementation restored pregnancy per AI in cows lacking a CL subjected to the initiation of the 5 -d timed AI protocol.

http://dx.doi.org/10.3168/jds.2012-6038.

Effect of presampling procedures on real-time PCR used for diagnosis of intramammary infections with Staphylococcus aureus in dairy cows at routine milk recordings. By Mahmmod et al., page 2226. The effect of presampling procedures (PSP), which included teat cleaning, discarding the first milk streams, and 70\% alcohol teat disinfection, on real-time PCR used for detection of Staphylococcus aureus was investigated in milk samples of 1,199 dairy cows. Following the farmers' routine premilking preparations, 624 cows of 1,199 cows were randomly selected for bacteriological culture preceded by PSP. The PSP decreased the cow's odds of being PCRpositive to 0.75 (95\% confidence interval: 0.58-0.97). Presampling procedures may improve the specificity of PCR for detection of Staphylococcus aureus by reducing number of false positives and should be applied before PCR sampling.

http://dx.doi.org/10.3168/jds.2012-6059.

The effect of price and production risks on optimal farm plans in Swiss dairy production considering 2 different milk quota systems. By Briner and Finger, page 2234. When managing farms, dairy producers face several sources of income risk, such as varying prices for milk. To reduce income variability, dairy producers can apply risk management strategies, such as storing feed to increase fodder availability in years with bad weather conditions. A change in the design of milk contracts could increase dairy farmers' income variability because it restricts their scope of action. Even if this is not the case, risk management strategies have to be adapted to the new contract to ensure the financial future of the farm.

http://dx.doi.org/10.3168/jds.2012-6086.

Genetic characterization of antimicrobial resistance in coagulase-negative staphylococci from bovine mastitis milk. By Frey et al., page $224 \%$ Coagulase-negative staphylococci (CNS) are increasingly isolated from cases of mastitis in cows. Continued antimicrobial treatment during persistent disease may promote antimicrobial resistance in the CNS population. The aims of this study were to determine the antimicrobial resistance profiles and resistance mechanisms of CNS from bovine milk and to determine the genetic relationships between the methicillin-resistant CNS isolates. Multidrug-resistant CNS species were detected within the heterogeneous CNS flora.

http://dx.doi.org/10.3168/jds.2012-6091.

Supplementation of conjugated linoleic acid in dairy cows reduces endogenous glucose production during early lactation. By Hötger et al., page 2258. Conjugated linoleic acid (CLA), especially the trans-10, cis-12 isomer, is well known for its reduction of milk fat. Less is known about its effect on glucose metabolism. In our study, CLA supplementation decreased endogenous glucose production (eGP) as well as gene expression of enzymes related to gluconeogenesis during early lactation. Because CLA reduced eGP, a glucose-sparing effect of CLA due to lower glucose utilization for milk fat synthesis and, likely, more efficient energy utilization in CLA cows is obvious.

http://dx.doi.org/10.3168/jds.2012-6127.

Data quality in the Norwegian dairy herd recording system: Agreement between the national database and disease recording on farm. By Espetvedt et al., page 2271. Disease events in Norwegian dairy cows are reported to a central database. Such disease databases are used extensively for herd advisory work and research, but control of data quality is frequently neglected. The essential step of data transfer from registered events on farm to the database was studied. Quality of data registered in the database was high with only around $2 \%$ being registered with the incorrect disease date or code. Still, around $12 \%$ of disease events registered on farm were not reported to the database.

http://dx.doi.org/10.3168/jds.2012-6143.

Comparison of metabolic, hematological, and peripheral blood leukocyte cytokine profiles of dairy cows and heifers during the periparturient period. By Jonsson et al., page 2283. The weeks surrounding birth present major physiological challenges for the pregnant dairy cow and can result in disease such as mastitis, ketosis, or milk fever. The present 
paper reports that dairy heifers in their first pregnancy (primipara) have a qualitatively different peripheral immune profile than older dairy cows that have experienced multiple pregnancies (multipara). These results indicate that further investigation is warranted to identify risk factors for metabolic and parturient disease in dairy cattle.

http://dx.doi.org/10.3168/jds.2012-6173.

Feeding barley grain-rich diets altered electrophysiological properties and permeability of the ruminal wall in a goat model. By Klevenhusen et al., page 2293. High-producing ruminants are generally fed large amounts of cereal grains to meet their energy requirements. This feeding strategy, though, can lead to acidic conditions in the rumen, which may affect ruminal functioning and damage the ruminal epithelium. The results of the present experiment demonstrated that excessive barley feeding over a period of $6 \mathrm{wk}$ decreases the barrier function of the ruminal epithelium in growing goats, which increases the risk of toxic compounds being translocated into the blood and lymphatic circulation.

http://dx.doi.org/10.3168/jds.2012-6187.

Bioavailability of quercetin from its aglycone and its glucorhamnoside rutin in lactating dairy cows after intraduodenal administration. By Gohlke et al., page 2303. Flavonoids are claimed to have health-promoting effects and are available as feeding supplements for cattle. However, bioavailability data of flavonoids in lactating dairy cows are scarce. To explore postruminal absorption and metabolism in dairy cows, we investigated the bioavailability of quercetin from its aglycone and the glucorhamnoside rutin after duodenal administration. Duodenal bioavailability of quercetin aglycone was comparable to bioavailability after oral administration in pigs, as reported previously. Quercetin from rutin was not absorbed in cows when administered duodenally.

http://dx.doi.org/10.3168/jds.2012-6234.

Cows and herds constitute distinct hierarchical levels of heterogeneity in the variability of and association between milk yield and pregnancy outcome in dairy cows. By Bello et al., page 2314. Understanding the factors that influence the variability of and the association between milk yield and fertility in dairy cows is critical to tailoring dairy management programs that optimize overall dairy performance. This study specifically investigates potential sources of heterogeneity in the variance of and the association between milk yield at and pregnancy outcome to first postpartum insemination, using recently developed statistical methodology that recognizes cows and herds as separate experimental units of performance.

http://dx.doi.org/10.3168/jds2012-6264.
Increased milk protein synthesis in response to exogenous growth hormone is associated with changes in mechanistic (mammalian) target of rapamycin (mTOR)C1-dependent and independent cell signaling. By Sciascia et al., page $232 \%$ Treatment with growth hormone is a well-established model used to study increased milk protein production in the mammary glands of lactating ruminants. This research was undertaken to study potential changes in mechanistic (mammalian) target of rapamycin (mTOR) pathway signaling in the mammary gland of lactating dairy cows treated with exogenous growth hormone. The new knowledge generated in this study may support the development of future technologies to enhance milk protein production on-farm.

http://dx.doi.org/10.3168/jds.2012-6267.

Short communication: Use of a mechanical brush by Holstein dairy cattle around parturition. By Newby et al., page 2339. The aim of this study was to investigate the use of a mechanical brush by cows around calving. When a mechanical brush was available, it was used by cows in both the precalving and maternity pens. While the calf was present and the cow brush was available, cows spent less time auto-licking, scratching themselves, or using the mechanical brush. While in the maternity pen, cows that had access to a mechanical brush licked their calf more than cows that did not have access to a brush.

http://dx.doi.org/10.3168/jds.2012-6016.

Hot topic: Investigating the risk of violative meat residues in bob veal calves fed colostrum from cows treated at dryoff with cephapirin benzathine. By Hausler et al., page 2349. The antibiotic cephapirin is approved by the US Food and Drug Administration for intramammary infusion in cows during the dry-off period. This pilot study investigated whether first-milking colostrum collected from such cephapirin-treated cows, when fed to newborn calves, would lead to violative levels of cephapirin residues in veal tissues. Colostrum was collected from cows treated with cephapirin at dry-off and fed to newborn bull calves, which were then killed at either 24 or $48 \mathrm{~h}$ of age. Cephapirin residues were not found in calf tissues using a kidney inhibition swab (KIS) screening test, or liquid chromatograph-tandem mass spectrometry analysis. This work indicates that potential transfer of cephapirin from cows treated on label at dry-off to calves via their colostrum may not be a significant source of cephapirin residues in veal tissues.

http://dx.doi.org/10.3168/jds.2012-5891.

Methane production and digestion of different physical forms of rapeseed as fat supplement in dairy cows. By Brask et al., page 2356. The methanereducing potential of different physical forms of rapeseed fat (rapeseed cake, whole cracked rapeseed, and 
rapeseed oil) and the effect on digestion in lactating dairy cows were tested using 4 lactating cows fitted with ruminal, duodenal, and ileal cannulas. On average, fat addition reduced methane energy loss by $14 \%$ without affecting intake, digestibility, or milk production. http://dx.doi.org/10.3168/jds.2012-5239.

Supplementing different ratios of short- and medium-chain fatty acids to long-chain fatty acids in dairy cows: Changes of milk fat production and milk fatty acids composition. By Sun et al., page 2366. The dietary addition of long-chain fatty acids (LCFA) or short- and medium-chain fatty acids (SMCFA) might promote milk fat synthesis. Our objective was to evaluate the effect of different ratios of SMCFA to LCFA on milk fat production and milk fatty acid composition in dairy cows. As the ratios of SMCFA to LCFA in the unprotected fatty acid supplementation increased, milk fat percentage and SMCFA concentration in milk fat tended to increase in a linear fashion. In conclusion, increasing ratios of SMCFA to LCFA could improve milk fat synthesis.

http://dx.doi.org/10.3168/jds2012-5356.

Effect of replacing soybean meal protein with protein from upland cottonseed, Pima cottonseed, or extruded Pima cottonseed on production of lactating dairy cows. By Broderick et al., page 2374. Pima cotton production is increasing but Pima cottonseed contains more of the antinutritive pigment gossypol than conventional upland cottonseed. Lactating dairy cows were fed diets in which half of the supplemental crude protein from soybean meal was replaced with protein from upland cottonseed, unprocessed Pima cottonseed, or Pima cottonseed that was subjected to an experimental extrusion process that heat-treated the protein and removed $73 \%$ of the oil. Results from this trial indicate that replacing $50 \%$ of the dietary soybean meal protein with protein from any of these cottonseed sources resulted in similar or greater milk yield and that Pima cottonseed and extruded Pima cottonseed cake are effective protein sources for lactating dairy cows. http://dx.doi.org/10.3168/jds.2012-5723.

Milk fat responses to butterfat infusion during conjugated linoleic acid-induced milk fat depression in lactating dairy cows. By Vyas et al., page 238\%. Previous studies have reported that the availability of short- and medium-chain fatty acids might be limiting during milk fat depression, and providing these fatty acids might increase milk fat output. To test this concept, we abomasally infused butterfat as source of short- and medium-chain fatty acids during milk fat depression in lactating cows. The results indicate that nutritional manipulation alone would be insufficient to prevent depression in milk fat.

http://dx.doi.org/10.3168/jds.2012-5861.

First-pass uptake and oxidation of glucose by the splanchnic tissue in young goats fed soy protein-based milk diets with or without amino acid supplementation. By Schönhusen et al., page 2400. Feeding milk diets with soy protein isolate seems to affect glucose status in preruminant goats, but has no effect on first-pass glucose uptake and glucose oxidation by the splanchnic tissues. However, the highest activities of mucosal lactase and maltase were observed after amino acid supplementation to soy protein. Higher phosphoenolpyruvate carboxykinase (PEPCK) activities in liver may point at elevated gluconeogenetic activities after amino acid supplementation in soy-fed kids.

http://dx.doi.org/10.3168/jds.2012-5933.

Effects of increasing amounts of corn dried distillers grains with solubles in dairy cow diets on methane production, ruminal fermentation, digestion, $\mathbf{N}$ balance, and milk production. By Benchaar et al., page 2413. Corn dried distillers grains with solubles (DDGS), the ethanol industry by-product, were fed to dairy cows (at $0,10,20$, and $30 \%$ of the diet) to examine their effects on enteric methane emissions and performance. Intake of dry matter increased whereas its apparent total-tract digestibility decreased as the proportion of DDGS in the diet increased at the expense of corn and soybean meal. Milk yield and protein yield increased whereas milk fat yield was not affected by increasing DDGS dietary proportion. As DDGS inclusion rate in the diet increased, methane emissions ( $\mathrm{g} / \mathrm{d}$ or as a proportion of gross energy intake) declined. Amount of methane produced per kilogram of milk produced also decreased with increasing proportions of DDGS in the diet. Feeding DDGS (up to 30\% of dietary dry matter) to dairy cows can help mitigate enteric methane emissions with no negative effects on animal performance.

http://dx.doi.org/10.3168/jds.2012-6037.

Effect of forage conservation method on ruminal lipid metabolism and microbial ecology in lactating cows fed diets containing a 60:40 forage to concentrate ratio. By Halmemies-BeauchetFilleau et al., page 2428. The effects of forage conservation on ruminal lipid metabolism and microbial ecology in lactating cows was examined in 2 complementary experiments. Conservation of grass by drying, but not ensiling, decreased forage fatty acid content. Compared with feeding fresh grass or grass silage, feeding diets based on grass hay lowered the extent of lipolysis and 
biohydrogenation of unsaturated fatty acids in the rumen, whereas the extent of fermentation in silo had minor effects. Forage conservation had no major influence on rumen protozoal counts or populations of specific ruminal bacteria capable of biohydrogenation. http://dx.doi.org/10.3168/jds.2012-6043.

Experimentally induced hyperchloremic and DLlactic acidosis in calves-An attempt to study the effects of oral rehydration on acid-base status. By Schwedhelm et al., page 2464. The common protocols that are used to study clinical aberrations of hyperchloremic and DL-lactic acidosis in calves are not suitable to study the effects of oral rehydration solutions on acid-base status because they greatly increase plasma volume. The repeated induction of DL-lactic acidosis in calves provoked unexpected adverse reactions, such as thromophlebitis and edema. More research is needed on the effects of D-lactate on vascular tissue. http://dx.doi.org/10.3168/jds.2012-6077.

Development of equations predicting methane emissions from ruminants. By Ramin and Huhtanen, page 2476. Dietary and animal factors play an important role on methane production from dairy cattle. Data from 52 published papers were analyzed to develop equations for predicting methane production from animal and dietary factors. Feed intake was the primary determinant of methane production, but the proportion of energy lost as methane decreased with increased feed intake. Methane production was positively related to diet digestibility and negatively to dietary fat concentration. The developed equations could be useful to improve the prediction of methane production and develop feeding and management strategies to mitigate methane production from ruminants.

http://dx.doi.org/10.3168/jds.2012-6095.

Jersey calf performance in response to highprotein, high-fat liquid feeds with varied fatty acid profiles: Intake and performance. By Bowen Yoho et al., page 2494. The most popular fat source in milk replacers (MR) intended for calves is edible lard. Edible lard primarily contains long-chain fatty acids, whereas Jersey whole milk contains a high concentration of medium-chain fatty acids (MCFA). Coconut oil is a rich source of MCFA, but data are limited on its use in MR for Jersey calves. This study investigated the effects of altering the fatty acid profile of MR with coconut oil on Jersey calf performance. Results indicated some possible benefits of MCFA on calf health and performance.

http://dx.doi.org/10.3168/jds.2012-6099.

Propionate induces the release of granules from bovine neutrophils. By Carretta et al., page $250 \%$. Metabolic disorders in dairy cattle may result in the accumulation of short-chain fatty acid (SCFA)- and lactate-producing ruminal acidosis, which is commonly characterized by an inflammatory response. In this study, we showed that propionate, one of the main SCFA, can induce the release of granules from bovine neutrophils, and we demonstrated the presence of SCFA receptors on neutrophils. These findings open new perspectives on modulation of the innate immune system function in metabolic situations in cattle. http://dx.doi.org/10.3168/jds.2012-6111.

Storage characteristics, nutritive value, energy content, and in vivo digestibility of moist large-rectangular bales of alfalfa-orchardgrass hay treated with a propionic acid-based preservative. By Coblentz et al., page 2521. Past studies have shown clear benefits from applying propionic acid-based preservatives to alfalfa hay made in $45-\mathrm{kg}$ small-rectangular bales, but their effectiveness in larger hay packages is not well documented or defined. A propionic acid-based preservative was applied to largerectangular bales of alfalfa-orchardgrass hay made at moistures ranging from 19.6 to $27.4 \%$; acid application rates were $0,0.6$, or $1.0 \%$ of wet bale weight. Acid treatment reduced spontaneous heating in these hays, regardless of initial bale moisture. Modest benefits were also observed for poststorage nutritive value of hays, as well as apparent digestibilities of dry matter and organic matter.

http://dx.doi.org/10.3168/jds.2012-6145.

Effects of plant enzyme inactivation or sterilization on lipolysis and proteolysis in alfalfa silage. By Ding et al., page 2536. High intake of polyunsaturated fatty acids has been shown to increase their concentration in ruminant products and, consequently be beneficial to human health. Therefore, most studies conducted on the fatty acid composition of silages are concerned with loss of lipolysis of polyunsaturated fatty acids during ensiling. However, whether the lipolysis during ensiling is mainly caused by microbial or plant lipases is still not clear. Our study results showed that extensive lipolysis occurred during ensiling of alfalfa, and plant enzymes played a major role in lipolysis and proteolysis. These findings might provide some useful information for developing methods to inhibit lipolysis in ensiled alfalfa silage.

http://dx.doi.org/10.3168/jds.2012-6438.

Short communication: Immediate and deferred milk production responses to concentrate supplements in cows grazing fresh pasture. By Roche et al., page 2544. Concentrate supplementation results in an immediate increase in milk production. This study investigated the size of the response beyond the period of supplementation. During the period of supplementation, yields of $4 \%$ fat-corrected milk, fat, 
and protein increased by $0.97,0.032$ and $0.048 \mathrm{~kg} / \mathrm{kg}$ of dry matter concentrate consumed. A further milk production response to supplements persisted for $3 \mathrm{wk}$ after supplementary feeding finished, with the greatest response being in milk fat. The total response to supplementary feeding was, on average, 19, 32, and $8 \%$ greater than the immediate response (i.e. during the period of supplementation) for $4 \%$ fat-corrected milk, fat, and protein yields, respectively. The deferred response must be accounted for when calculating production responses to supplements.

http://dx.doi.org/10.3168/jds.2012-4626.

Short communication: Effect of oilseed supplementation of an herbage diet on ruminal fermentation in continuous culture. By Soder et al., page 2551. The aim of this study was to evaluate the effects of oilseed supplementation (flaxseed, canola seed, or sunflower seed) of an herbage-based diet on nutrient digestibility, fermentation profile, and bacterial nitrogen synthesis in a dual-flow continuous culture fermentor system. Supplementation with oilseeds moderately affected culture fermentation compared with an all-herbage diet. Oilseeds tested herein may be considered as an alternative energy supplement for grazing dairy cows, particularly during times of low availability of corn.

http://dx.doi.org/10.3168/jds.2012-6426.

Milk metabolites and their genetic variability. By Wittenburg et al., page 255\%. Metabolites represent a new class of milk traits with unknown genetic background. Their heritability and mode of inheritance were investigated based on genomic and pedigree information. Milk metabolite levels seem to mostly reflect environmental or temporal variable status, but genetics significantly contributed to the phenotypic variability of some metabolites.

http://dx.doi.org/10.3168/jds.2012-5635.

Differences in milk fat composition predicted by mid-infrared spectrometry among dairy cattle breeds in the Netherlands. By Maurice-Van Eijndhoven et al., page 2570. Breed differences in detailed milk fat composition and content of individual fatty acids, predicted using mid-infrared spectrometry, were quantified among different dairy cattle breeds in the Netherlands. Differences among breeds in detailed milk fat composition were shown to be strongly related to total fat percentage. Knowledge on variation in detailed milk fat composition among cows is of interest for the dairy industry because fat composition is associated with processability, human health, and methane emissions.

http://dx.doi.org/10.3168/jds.2012-5793.
Gene coexpression network analysis identifies genes and biological processes shared among anterior pituitary and brain areas that affect estrous behavior in dairy cows. By Kommadath et al., page 2583. The expression of estrous (sexually receptive) behavior, a key fertility trait in dairy cows, has been declining over the past few decades, in both intensity and duration. Improved knowledge of the genomic factors underlying this trait could lead to the development of novel management strategies to monitor and improve reproductive performance in dairy cows; for example, biomarkers for estrus detection. Here, we identified genes and biological processes shared among the bovine anterior pituitary and 4 brain areas that act together to regulate estrous behavior by investigating networks of co-expressed genes between these tissues. http://dx.doi.org/10.3168/jds.2012-5814.

Genetic parameters for hoof lesions and their relationship with feet and leg traits in Canadian Holstein cows. By Chapinal et al., page 2596. Genetic parameters of hoof infectious and horn lesions, and their genetic correlations with conformation traits, were estimated using hoof trimming and classification records from Canadian Holsteins. Hoof lesions showed low heritability, yet sufficient genetic variation for genetic improvement through direct selection. We found a positive genetic correlation between front and rear infectious lesions, and front and rear horn lesions, but not between infectious and horn lesions. Genetic correlations of hoof lesions with conformation traits were low to moderate. Standardization of hoof-trimming records should be encouraged to be included in routine genetic evaluations for long-term improvement of hoof health. http://dx.doi.org/10.3168/jds.2012-6071.

Sterol regulatory element binding transcription factor 1 (SREBF1) polymorphism and milk fatty acid composition. By Nafikov et al., page 2605. High percentages of saturated fatty acids (SFA) and of individual SFA such as myristic (14:0) and lauric (12:0) acids in milk and other dairy products is a risk factor for developing cardiovascular diseases, the leading cause of death worldwide. The main goal of this study was to develop animal breeding strategies that would allow the selection of animals producing healthier milk with low percentages of myristic and lauric acids. http://dx.doi.org/10.3168/jds.2012-6075.

Integration of epidemiology into the genetic analysis of mastitis in Swedish Holstein. By Windig et al., page 261\%. Heritability of mastitis, and diseases in general, tends to be low. One reason is that generally no distinction is made between animals that are healthy because they were never exposed to patho- 
gens and animals that are healthy because they are resistant to pathogens. To account for this, we quantified the prevalence of clinical and subclinical mastitis in Swedish Holstein herds and analysed the genetics with a reaction norm approach. We observed no clear effect of herd prevalence on the heritability of clinical and subclinical mastitis.

http://dx.doi.org/10.3168/jds.2012-6076.

Variance component and breeding value estimation for genetic heterogeneity of residual variance in Swedish Holstein dairy cattle. By Rönnegård et al., page 262\%. Cows differ not only in their mean for a trait within a lactation period but also in the variation around that mean. This study shows that environmental variation has a heritable component within lactation periods for both milk yield and somatic cell count (SCC) in Holstein dairy cattle. For a trait such as SCC, this may be of particular importance if too-high values carry a price penalty, and decreasing both the mean and the variance by selection would be beneficial.

http://dx.doi.org/10.3168/jds.2012-6198.

Short communication: Imputing genotypes using PedImpute fast algorithm combining pedigree and population information. By Nicolazzi et al., page 2649. Routine genomic evaluations frequently include a preliminary imputation step, requiring high accuracy and reduced computing time. A new algorithm, namely PedImpute, was developed and compared to Findhap and Beagle algorithms using multiple-country Holstein genotypes with different density. PedImpute was slightly more accurate and faster than Findhap and Beagle when sire, dam, and maternal grandsire were genotyped at high density. Beagle performed better than PedImpute and Findhap for the other scenarios, although it required much greater computing time and resources. Considering the accuracy results and the computer requirements of all algorithms, the Italian Holstein Association has implemented PedImpute in its routine genomic evaluation.

http://dx.doi.org/10.3168/jds.2012-6062.

Short communication: Estimation of genetic parameters for residual feed intake and feeding behavior traits in dairy heifers. By Lin et al., page 2654. Feeding behavior traits could become alternatives for measuring feed efficiency in livestock if modest genetic correlations exist between these traits. Such indirect measures of residual feed intake (RFI) could reduce the cost and time associated with direct estimates of feed efficiency, and may provide a better understanding of the underlying biological mechanisms controlling feed efficiency. Here, genetic parameters for feeding behavior and RFI were assessed using data from 842 Holstein-Friesian heifers. We concluded that although some feeding behavior traits had modest genetic and phenotypic correlations with RFI, the necessity of measuring feed intake remained a limitation. Genomic selection tools for the trait of interest; that is, RFI, may be a better approach for selecting animals with desirable feed efficiency. http://dx.doi.org/10.3168/jds.2012-6134.

Short communication: Genetic evaluation of mobility for Brown Swiss dairy cattle. By Wright et al., page 265\%. The Brown Swiss Cattle Breeders' Association of the USA began scoring mobility in 2007. This trait measures ease of movement and comfort while standing and is scored on a scale of 50 to 99 . Heritability of mobility was estimated to be $21 \%$. Rear legs (rear view) is a component of mobility, and mobility is a component of final score, so all were found to be highly correlated. Mobility may increase accuracy and timeliness of predictions of productive life by giving a more accurate assessment of the structural soundness required for longevity. Mobility genetic evaluations became official in August 2012.

http://dx.doi.org/10.3168/jds.2012-6193.

Opportunities and constraints to improving milk quality in Ireland: Enabling change through collective action. By Devitt et al., page 2661. Improving milk quality is important for Ireland, and action on quality is being taken by Animal Health Ireland (AHI). Collective action is when individuals work together to achieve a common goal. Challenges exist in trying to achieve collective action. Interviews were conducted with members of the Irish dairy industry. Results indicated agreement on the need to improve milk, but disagreement on whose responsibility it is to do so. Concerns were expressed about the commitment to work together to achieve better milk. Understanding how collective action works is important for AHI when bringing industry members together to improve milk quality.

http://dx.doi.org/10.3168/jds.2012-6001.

Dairy calving management: Description and assessment of a training program for dairy personnel. By Schuenemann et al., page 2671. The objective of the present study was to assess the effectiveness of a comprehensive calving management program designed to enhance the flow of applied, research-based, calving information to dairy personnel. The materials presented and the implemented delivery methods substantially increased the knowledge level of the attendees. Dairy personnel reported that the overall program, presentations, and discussions were useful. Importance of open communication within the farm team, recognizing the landmarks for parturition, signs of calving progress, estimated reference times for intervention, and strategies to correct abnormal presentation, position, or posture 
were listed as learned concepts with immediate field application.

http://dx.doi.org/10.3168/jds.2012-5976.

Economic comparison of reproductive programs for dairy herds using estrus detection, timed AI, or a combination of both. By Galvão et al., page 2681. Reproductive performance is critical for dairy farm profitability. A stochastic dynamic model was developed to compare the economic outcome of reproductive programs using estrus detection (ED), timed AI (TAI), or a combination of both (TAI-ED). Ovsynch preceded by presynchronization with 2 injections of prostaglandin was the TAI program evaluated. Accuracy of ED and compliance with the injections for the TAI program were of particular interest. Profits were higher for ED if service rate (SR) was $\geq 50 \%$. Combining TAI and ED increased profits within each level of accuracy or compliance, but the model with $60 \%$ SR and 95\% accuracy was as profitable or more profitable than TAI-ED models with lower SR, accuracy, or compliance. Therefore, herds can improve their profits by combining TAI and ED as reproductive management; however, if a herd can achieve high SR with high accuracy or have high compliance with injections, using only ED or TAI might be more profitable than trying to do both.

http://dx.doi.org/10.3168/jds.2012-5982.

Determining the efficacy of a postmilking teat disinfectant following experimental exposure of teats to mastitis pathogens. By Schukken et al., page 2694. The objective of this paper was to provide a standardized protocol for the evaluation of teat disinfectants following experimental exposure to mastitis pathogens. Protocols for experimental exposure trials with either negative controls or positive controls are described. The described protocols should be used for trials that may be published in the National Mastitis Council summary of peer-reviewed publications on efficacy of postmilking teat disinfectants. http://dx.doi.org/10.3168/jds.2012-6222.

Preliminary study to assess mycotoxin concentrations in whole corn in the California feed supply. By Krout-Greenberg et al., page 2705. Mycotoxins are naturally occurring environmental contaminants found in food and feed products. Produced as secondary metabolites by filamentous fungi, mycotoxins can have acute and chronic effects. Fumonisins were the predominant mycotoxins found in corn used for animal feed, but all concentrations were below the federal action level. Deoxynivalenol and aflatoxins were also found at lower prevalence. No samples containing deoxynivalenol were above the federal action level and only 1 of 14 samples with aflatoxins was above the federal action level. Corn grain entering California is monitored for mycotoxin contamination as a feed/food safety action.

http://dx.doi.org/10.3168/jds.2012-5957.

Visualization of the transmission of direct genomic values for paternal and maternal chromosomes for 15 traits in US Brown Swiss, Holstein, and Jersey cattle. By Cole and Null, page 2713. In response to the recent availability of efficient haplotyping procedures for large numbers of animals, and the interest in those data, an online query to display that information has been developed. Direct genomic values of paternal and maternal haplotypes are available for 220,671 Brown Swiss, Holstein, and Jersey bulls and cows that received genomic evaluations in August 2012. Query results are available to all users, and several options for controlling output are available. Some quantitative genetic principles are demonstrated using query output. Challenges related to the application of haplotypes to mating decisions are discussed, and strategies for use are described. http://dx.doi.org/10.3168/jds.2012-6008. 